\title{
Shifts in Bud and Leaf Hardiness during Spring Growth and Development of the Cranberry Upright: Regrowth Potential as an Indicator of Hardiness
}

\author{
Beth Ann A. Workmaster and Jiwan P. Palta ${ }^{1}$ \\ Department of Horticulture, University of Wisconsin, 1575 Linden Drive, Madison, WI 53715
}

\begin{abstract}
AdDitional INDEX words. Vaccinium macrocarpon, cold hardiness, freezing stress resistance, phenology, nonlinear regression, Gompertz function, $\mathrm{LT}_{50}$

Aвstract. 'Stevens' cranberry (Vaccinium macrocarpon Ait.) terminal bud freezing stress resistance was assessed by nonlinear regression utilizing relative scoring of the post-thaw bud growth and development based on defined bud stages 2 weeks following controlled freezing tests. Bud stages tested were chosen based on a phenology profile from each sampling date throughout the spring season. Previous year (overwintering) leaf freezing stress resistance was evaluated after both 2 days (injury) and 2 weeks (survival). The Gompertz function with a bootstrapping method was used to estimate the tissues' relative freezing stress resistance as the $\mathbf{L T}_{50}$. Bud injury levels $\left(\mathrm{LT}_{50}\right)$ were expressed as the temperatures at which the mean potential regrowth capability was impaired by $50 \%$, as compared with the unfrozen controls. In leaves, the $\mathbf{L T}_{50}$ is the temperature at which $\mathbf{5 0 \%}$ injury (2-day evaluation) or survival (2-week evaluation) was modeled to occur. Dramatic changes in terminal bud relative freezing stress resistance occurred both within and between the tight and swollen bud stages. These results clearly show that seasonal changes in freezing stress resistance do not necessarily parallel changes in crop phenology and bud development. These results indicate that some physiological, biochemical, or fine anatomical changes may explain the seasonal loss in hardiness within a visual bud stage. Previous year leaves may possess the ability to recover from freeze-induced injury, as leaf survival was found to be the most reliable indicator of cranberry leaf hardiness. Major shifts in phenology and bud and leaf hardiness coincided with the rise of minimum canopy-level air temperatures to above freezing. The nonlinear regression technique utilized made it possible to estimate $\mathbf{L T}_{50}$ with data points comprising half or more of the sigmoidal dose response curve. Our study provides precise and quantitative estimates of the cold hardiness changes in cranberry terminal buds and leaves in spring. From precise estimates we were able to define critical temperatures for the impairment of cranberry bud growth. This is the first systematic study of cranberry terminal bud cold hardiness and spring bud development in relation to changes in the soil and air temperatures under natural conditions. Our study shows that regrowth assessment of the cranberry upright inherently describes the composite effects of freezing stress on plant health.
\end{abstract}

Due to their low elevations, cranberry growing areas are often subject to frosts, events that are possible even in summer (Dana, 1990). Sprinkle irrigation is the main frost protection method used by Wisconsin growers. To protect the vines through the winter, cultivated cranberries are flooded to form a protective layer of ice around and above the vines. Bud hardiness is lost quickly in spring when development and growth resumes (Abdallah and Palta, 1989). Classification schemes for stages of bud development and corresponding hardiness levels have been developed for apple (Malus xdomestica Borkh.), pear (Pyrus communis L.), sweet cherry (Prunus avium L.), peach (Prunus persica Batsch), prune (Prunus domestica L.), and apricot (Prunus armeniaca L.) (Proebsting and Mills, 1978), grape (Vitis vinifera L.) (Johnson and Howell, 1981a, 1981b), and rabbiteye blueberry (Vaccinium ashei Reade) (Spiers, 1978). Attempts to relate freezing stress resistance to spring developmental stages have been reported for cranberries grown in Massachusetts (DeMoranville, 1998; DeMoranville and DeMoranville, 1997; Roberts and DeMoranville, 1985) using potted sods collected from commercial beds. Stages of bud development identified in these reports ranged

Received for publication 30 June 2005. Accepted for publication 21 Feb. 2006. We thank Bjorn Karlsson for field assistance and Peter Crump for writing the SAS programs. Teryl Roper provided the original drawing that was adapted for Fig. 1. This study was supported by a grant from Wisconsin Cranberry Board and by the College of Agriculture and Life Sciences, Univ. of Wisconsin-Madison.

1To whom reprint requests should be addressed. E-mail address: jppalta@wisc. edu from spring dormant buds to bloom, and shifts in hardiness were estimated to be from about $-9{ }^{\circ} \mathrm{C}$ to about $-1{ }^{\circ} \mathrm{C}$, respectively. However, preliminary studies by Abdallah and Palta (1989) estimated much greater changes in freezing stress resistance using controlled freezing tests.

Beside these general estimates, there is little published work on freezing stress resistance of the cranberry plant. Furthermore, there is little agreement on the hardiness of the cranberry plant, even in its dormant state (Doughty and Shawa, 1966; Eck, 1990; Roberts and DeMoranville, 1985). Due to the supercooling of various tissues, ice nucleation is necessary in freezing stress experiments to obtain precise estimates of freezing stress resistance; yet this has not been used in most cranberry studies (DeMoranville and DeMoranville, 1997; Eaton and Mahrt, 1977; Reader, 1979).

The main objective of our study was to define critical temperatures for the impairment of cranberry bud growth. A unique aspect of our study is the assessment of bud freezing stress resistance by nonlinear regression utilizing relative scoring of bud growth and development based on defined bud stages. Bud development and budbreak can be impaired by freezing temperatures (Spiers, 1978). Since multiple bud stages can be present in the field at a given time, we assessed the effect of freezing temperatures for the leading bud stages at each test sample date.

Plant tissue response to freezing stress is characterized by an "S-shape," or sigmoidal, curve bounded by a lower and an upper asymptote (Zhu and Liu, 1987). In plant cold hardiness studies, the term $\mathrm{LT}_{50}$ has been used to denote the temperature at which $50 \%$ of the samples or plants were killed, $50 \%$ of the tissue was 
damaged, or $50 \%$ of the ions or other cell contents leaked from the cells. The $\mathrm{LT}_{50}$ injury level has been interpreted as the critical temperature for tissue recovery (Sakai and Larcher, 1987), although it has also been shown that 50\% ion leakage does not necessarily relate to 50\% cell death (Palta et al., 1977a, 1977b). Other arbitrary levels of injury, such as $\mathrm{LT}_{10}, \mathrm{LT}_{20}$, etc., have also been applied to freezing stress resistance data to indicate severity of damage. To be meaningful, these critical injury levels must be related to empirical knowledge regarding the impairment of cellular function or survivability of the tissue or plant (Luoranen et al., 2004; Stergios and Howell, 1973). Such methodology has not been employed for the study of cranberry plant freezing stress resistance.

Empirical mathematical models have been used recently to characterize the sigmoidal plant response to environmental stress. Although straight line techniques have been used (Holt and Pellet, 1981), computer simulations using sigmoid functions have proven to be more applicable (Anisko and Lindstrom, 1995; Jánacek and Prásil, 1991; Lim et al., 1998; Luoranen et al., 2004; von Fircks and Verwijst, 1993; Zhu and Liu, 1987). In addition to the interpolation of various injury levels (e.g., $\mathrm{LT}_{10}$ or $\mathrm{LT}_{50}$ ), the inflection point of the curve indicates the temperature at which the greatest rate of injury occurred $\left(\mathrm{T}_{\max }\right)$.

Asymmetric functions can often better describe biological responses to stress than the logistic function since such data are often skewed in their distribution (von Fircks and Verwijst, 1993). The Richards function has been used to model the effect of plant freezing stress with both electrolyte leakage data (Anisko and Lindstrom, 1995; von Fircks and Verwijst, 1993) and shoot mortality data (von Fircks and Verwijst, 1993). Although the results of these studies produced seemingly meaningful results, use of the Richards function has been criticized on the grounds that it requires the estimation of an additional parameter and that it has high intrinsic nonlinearity, resulting in the parameter estimates to be severely biased (Ratkowsky, 1990). Lim et al. (1998) compared the suitability of the Richards and the Gompertz functions for use in evaluating freeze injury electrolyte leakage data. Although there was no significant difference between the performances of the two functions, these authors chose the Gompertz function to estimate the $\mathrm{LT}_{50}$ and $\mathrm{T}_{\max }$ values because it had fewer parameters to estimate and that it fit relatively better when compared with the general linear model.

Our study is an attempt to evaluate the freezing stress resistance of the cranberry upright by quantifying the competence of terminal buds following a freeze-thaw stress. We used the Gompertz function with a bootstrapping method to evaluate the critical temperatures related to various levels of freezing stress damage. From precise measurements we attempted to determine systematic changes in cranberry bud hardiness in relation to bud development and changes in the soil and air temperatures. Changes in hardiness between and within bud stages were estimated.

\section{Materials and Methods}

Plant material. Samples of 'Stevens' uprights were collected from a bed in central Wisconsin throughout the spring seasons of 1997 and 1998. Preliminary fieldwork was conducted in 1996. Each year the sampling period began when the ice cover was fully melted and beds could be accessed. This date was called the "ice-off" date. The sampling period continued from the ice-off date until the beginning of bloom. Samples were collected on 21 dates in 1997, and on 15 dates in 1998. On each sample date, cuttings were taken from nine random locations in the bed. For each cutting location, all of the uprights from an approximately $50 \times 13$-cm strip were cut $(\approx 350$ to 400 uprights). Samples were kept on ice for transport to Madison, Wis. Unless otherwise noted, hardiness values and patterns described are from the 1997 results, including 1998 data where relevant.

Uprights were sorted according to previously defined terminal bud stages (Workmaster et al., 1997) (Fig. 1). The stage of "earlyhook" was added at the time of sorting. Controlled freezing tests were performed on uprights of the most advanced bud stages that each constituted about $10 \%$ or more of the bud stages present (Tables 1 and 2). Bud stage categories were tested from all 21 sampling dates in 1997, and from five of the 15 sampling dates in 1998 (6 and 27 Apr.; 5, 7, and 14 May).

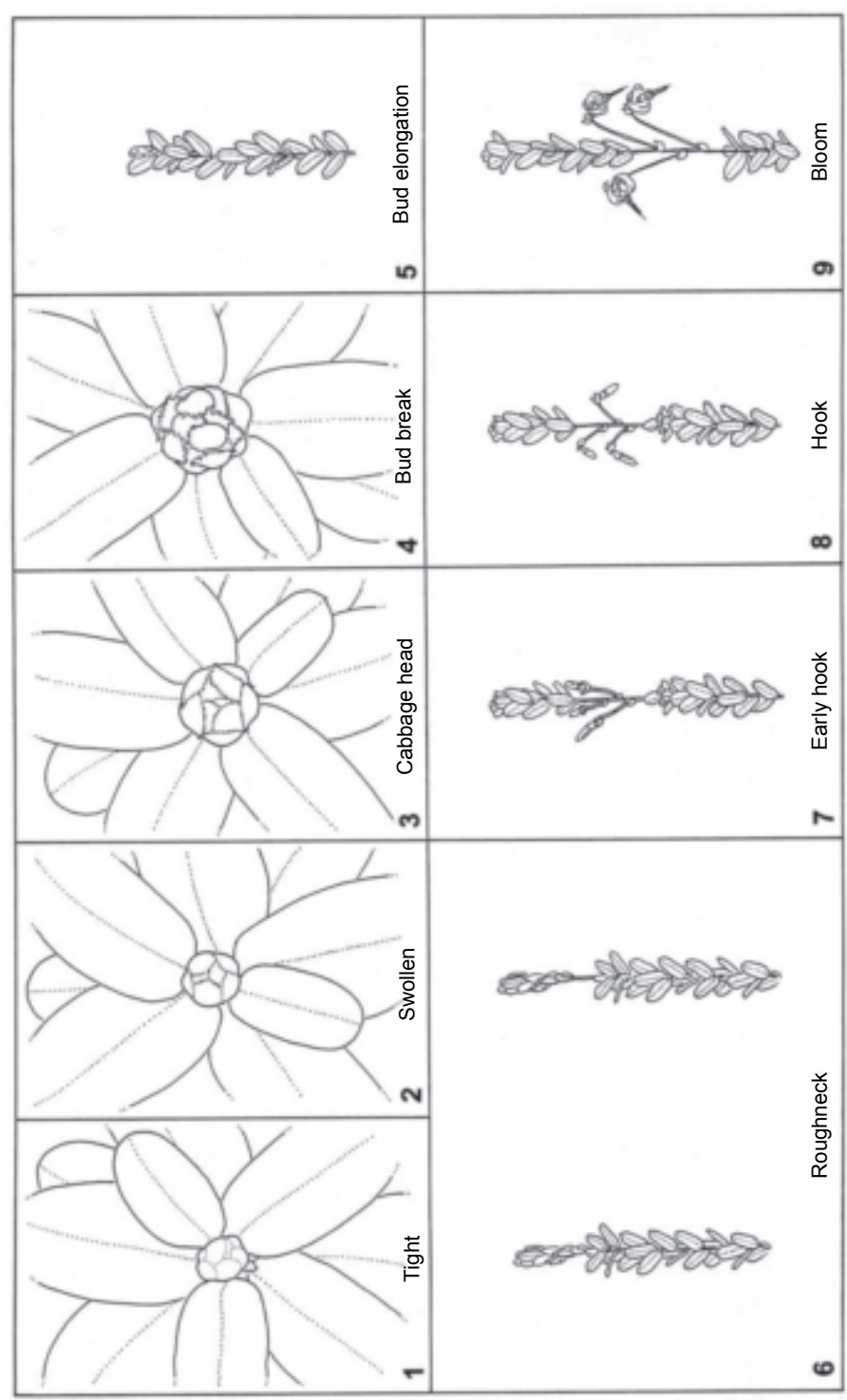

Fig. 1. Developmental changes in the cranberry terminal bud during spring; 1 = tight, dormant bud; 2 = swollen, bud enlargement; 3 = cabbage-head, pronounced swelling marked by displacement of bud scales; 4 = budbreak; 5 = bud elongation, extension of new growth $(\approx 1 \mathrm{~cm})$ showing vegetative growth; $6=$ roughneck, further extension of new growth prior to elongation of pedicels, resulting in the flower buds giving the new stem a bumpy appearance; $7=$ early-hook, initial elongation of pedicels; $8=$ hook, full elongation of pedicels forming characteristic hook shape; and $9=$ bloom. Drawing based upon pictures by Workmaster et al. (1997). 
Table 1. Percentages of cranberry bud stages present in the field on 21 sampling dates in Spring 1997. Values are means of nine sampling locations within the bed. At each location 350-400 uprights were sampled. Categories used for controlled freezing tests are in bold face.

\begin{tabular}{lrrrrrrrrr}
\hline & \multicolumn{7}{c}{ Proportion of buds in each stage $(\%)$} & & \\
Date & \multicolumn{1}{c}{ T } & SW & CH & BB & BE & RN & EH & HK & BL \\
\hline 15 Apr. & $\mathbf{1 0 0 . 0}$ & --- & --- & --- & --- & --- & --- & --- & --- \\
22 Apr. & $\mathbf{1 0 0 . 0}$ & --- & --- & --- & --- & --- & --- & --- & --- \\
27 Apr. & $\mathbf{1 0 0 . 0}$ & --- & --- & --- & --- & --- & --- & --- & --- \\
29 Apr. & $\mathbf{1 0 0 . 0}$ & --- & --- & --- & --- & --- & --- & --- & --- \\
2 May & $\mathbf{1 0 0 . 0}$ & --- & --- & --- & --- & --- & --- & --- & --- \\
5 May & $\mathbf{8 7 . 9}$ & $\mathbf{1 2 . 1}$ & --- & --- & --- & --- & --- & --- & --- \\
9 May & $\mathbf{9 0 . 2}$ & $\mathbf{9 . 8}$ & --- & --- & --- & --- & --- & -- & --- \\
13 May & $\mathbf{8 2 . 5}$ & $\mathbf{1 7 . 5}$ & --- & --- & --- & --- & --- & --- & --- \\
16 May & $\mathbf{8 2 . 7}$ & $\mathbf{1 7 . 3}$ & --- & --- & --- & --- & --- & --- & --- \\
20 May & $\mathbf{6 0 . 3}$ & $\mathbf{3 9 . 7}$ & --- & --- & --- & --- & --- & --- & --- \\
22 May & $\mathbf{6 7 . 8}$ & $\mathbf{3 1 . 9}$ & 0.2 & 0.1 & --- & --- & --- & --- & --- \\
24 May & $\mathbf{5 5 . 1}$ & $\mathbf{4 4 . 4}$ & 0.5 & --- & --- & --- & --- & --- & --- \\
26 May & $\mathbf{2 6 . 4}$ & $\mathbf{6 4 . 4}$ & 8.7 & 0.5 & --- & --- & --- & --- & --- \\
28 May & $\mathbf{3 7 . 3}$ & $\mathbf{4 7 . 8}$ & $\mathbf{1 4 . 1}$ & 0.8 & --- & --- & --- & --- & --- \\
30 May & 30.7 & $\mathbf{3 8 . 2}$ & $\mathbf{2 2 . 3}$ & $\mathbf{8 . 8}$ & --- & --- & --- & --- & --- \\
1 June & 24.2 & $\mathbf{2 2 . 8}$ & $\mathbf{3 5 . 6}$ & $\mathbf{1 4 . 7}$ & 2.7 & --- & --- & --- & --- \\
3 June & 9.0 & 12.9 & $\mathbf{2 3 . 7}$ & $\mathbf{2 9 . 3}$ & $\mathbf{2 4 . 2}$ & 1.0 & --- & ---- & ---- \\
5 June & 1.8 & 2.8 & 9.7 & $\mathbf{1 7 . 4}$ & $\mathbf{4 0 . 9}$ & $\mathbf{2 7 . 3}$ & --- & --- & --- \\
11 June & 2.2 & 2.7 & 1.9 & 3.8 & $\mathbf{1 8 . 2}$ & $\mathbf{6 6 . 9}$ & 4.2 & 0.2 & ---- \\
18 June & 2.0 & 2.1 & 0.4 & 0.4 & 3.3 & $\mathbf{4 4 . 4}$ & $\mathbf{2 9 . 6}$ & $\mathbf{1 7 . 8}$ & --- \\
25 June & 0.6 & --- & --- & --- & 0.1 & 7.4 & 21.9 & $\mathbf{6 7 . 8}$ & 2.1 \\
\hline
\end{tabular}

zT = tight, $\mathrm{SW}=$ swollen, $\mathrm{CH}=$ cabbage-head, $\mathrm{BB}=$ budbreak, $\mathrm{BE}=$ bud elongation, $\mathrm{RN}=$ roughneck, $\mathrm{EH}=$ early-hook, $\mathrm{HK}=$ hook, $\mathrm{BL}=$ bloom.

Table 2. Estimated $\mathrm{LT}_{50}$ values for cranberry upright terminal buds sampled in Spring 1997. $\mathrm{LT}_{50}$ is the temperature at which bud growth is impaired 50\%, as compared to controls. Estimates are means of multiple runs $(\mathrm{n}=100)$ of the freezing stress response curve $(n=27$ at each test temperature) using the Gompertz function. A bootstrapping with replacement method was used to generate new data sets at each test temperature. Values given with a $<$ sign are the lowest test temperature on that date for the stage given, which was not cold enough to yield a sufficient response curve.

\begin{tabular}{|c|c|c|c|c|c|c|c|}
\hline \multirow[b]{2}{*}{ Date } & \multicolumn{7}{|c|}{$\mathrm{LT}_{50}$ by bud stage ${ }^{\mathrm{z}}\left[\right.$ mean $\left.\pm \mathrm{SE}\left({ }^{\circ} \mathrm{C}\right)\right]$} \\
\hline & $\mathrm{T}$ & SW & $\mathrm{CH}$ & $\mathrm{BB}$ & $\mathrm{BE}$ & RN & EH \\
\hline 15 Apr. & $<-22$ & & & & & & \\
\hline 22 Apr. & $<-22$ & & & & & & \\
\hline 27 Apr. & $<-20$ & & & & & & \\
\hline 29 Apr. & $<-22$ & & & & & & \\
\hline 2 May & $<-22$ & & & & & & \\
\hline 5 May & $<-20$ & $-18.2 \pm 0.6$ & & & & & \\
\hline 9 May & $-13.1 \pm 0.1$ & $-13.9 \pm 0.1$ & & & & & \\
\hline 13 May & $-14.9 \pm 0.1$ & $-11.2 \pm 0.1$ & & & & & \\
\hline 16 May & $-16.3 \pm 0.1$ & $-14.1 \pm 0.1$ & & & & & \\
\hline 20 May & $-13.0 \pm 0.1$ & $-11.2 \pm 0.0$ & & & & & \\
\hline 22 May & $-14.3 \pm 0.1$ & $-11.5 \pm 0.1$ & & & & & \\
\hline 24 May & $-9.7 \pm 0.1$ & $-10.0 \pm 0.0$ & & & & & \\
\hline 26 May & $-8.5 \pm 0.0$ & $-8.6 \pm 0.0$ & & & & & \\
\hline 28 May & $-8.7 \pm 0.1$ & $-7.3 \pm 0.0$ & $-5.6 \pm 0.0$ & & & & \\
\hline 30 May & & $-6.7 \pm 0.0$ & $-3.9 \pm 0.0$ & & & & \\
\hline 1 June & & $-7.4 \pm 0.1$ & $-7.8 \pm 0.0$ & $-4.3 \pm 0.0$ & & & \\
\hline 3 June & & & $-5.5 \pm 0.0$ & $-4.6 \pm 0.1$ & & & \\
\hline 5 June & & & & $-6.3 \pm 0.7$ & $-2.9 \pm 0.0$ & $-2.7 \pm 0.0$ & \\
\hline 11 June & & & & & $-3.2 \pm 0.0$ & $-2.6 \pm 0.0$ & \\
\hline 18 June & & & & & & $-3.5 \pm 0.0$ & $-2.4 \pm 0.0$ \\
\hline
\end{tabular}

$\overline{\mathrm{z}} \mathrm{T}=$ tight, $\mathrm{SW}=$ swollen, $\mathrm{CH}=$ cabbage-head, $\mathrm{BB}=$ budbreak, $\mathrm{BE}=$ bud elongation, $\mathrm{RN}=$ roughneck, $\mathrm{EH}=\mathrm{early}-$ hook. 
Controlled FREeZING TeSts. A procedure similar to Abdallah (1989) and Steffen et al. (1989) was used in controlled freezethaw stress tests. In preparation for the controlled freezing test, uprights were rinsed several times in cold tap water to remove dirt and debris, cut to a length of $10 \mathrm{~cm}$ under water, shaken dry, and placed in 70-mL test tubes. Nine (1997 and 1998) to 12 (some dates in 1998) replicate tubes were used at each test temperature, with each tube containing three uprights, for each bud stage tested. Freezing tests were performed in a circulating glycol bath (model 2946; Forma Scientific, Marietta, Ohio). The temperature of the bath was lowered $0.5^{\circ} \mathrm{C}$ per $0.5 \mathrm{~h}$ from 0 to $-6{ }^{\circ} \mathrm{C}$, then $1.0^{\circ} \mathrm{C}$ per $0.5 \mathrm{~h}$ to $-12{ }^{\circ} \mathrm{C}$, and $2.0^{\circ} \mathrm{C}$ per $0.5 \mathrm{~h}$ until the minimum test temperature was reached. To ensure ice nucleation, a chip of ice was added to each tube at $-1{ }^{\circ} \mathrm{C}$, and then the tube was shaken three times in the bath. Bath temperature was held at $-1^{\circ} \mathrm{C}$ for an additional $1 \mathrm{~h}$ to allow for equilibrium at this temperature. The temperature of the bath was monitored by a copper-constantan thermocouple placed in a $70-\mathrm{mL}$ test tube containing $\approx 2 \mathrm{~mL}$ distilled water. Tubes were removed at various test temperatures and placed on ice overnight. Control tubes were kept on ice for the duration of the experiment. The next morning tubes were transferred to a $4{ }^{\circ} \mathrm{C}$ cold room for thawing and held there, shaded, for an additional $2 \mathrm{~d}$ to allow for recovery from injury.

Freezing stress inJury evaluation. An initial evaluation of upright health was performed after the recovery period (2-d evaluation). This evaluation focused on injury to previous year (overwintering) leaves and current year growth, when present. Data from the evaluation of all the uprights sampled on a given date were combined to determine hardiness of previous year leaves. New growth from uprights sampled at the stage of bud elongation and beyond was scored for darkening and watersoaking (these data not included here). Previous year leaves were scored for total area of darkening and watersoaking on a scale from 0 to 10 , with 0 showing no injury and 10 being completely darkened and watersoaked. After the initial evaluation, uprights were returned to their respective test tubes, given $\approx 5 \mathrm{~mL}$ fresh distilled water, and set out on a plant cart maintained at room temperature under cool white fluorescent lights of $\approx 125 \mu \mathrm{mol} \cdot \mathrm{m}^{-2} \cdot \mathrm{s}^{-1}$ photosynthetically active radiation for regrowth.

Two weeks after the imposition of the freezing stress, leaves were evaluated for survival and buds were rated for viability (2week evaluation). Leaf survival was rated on a percentage scale describing the percentage of leaves that had remained attached to the stem and were green (100\% indicating all the leaves remained green attached to the stem). The viability of terminal buds was evaluated by rating each bud for the bud stage it had attained over the regrowth period, similar to the approach used by Spiers (1978). Each bud was assigned a number that corresponded to the bud stage attained ( $1=$ tight, 9 = bloom; as shown in Fig. 1 ). We evaluated the progress in bud development (bud stages advanced) as a quantitative indicator of the ability of the bud to attain normal development following freeze-thaw stress. Lack of advancement in bud development indicated impairment by freeze-thaw stress.

Data ANAlysis. The Gompertz function was fitted to the bud viability and leaf score data, similar to Lim et al. (1998). The Gauss-Newton method was applied using the NLIN procedure of SAS (SAS Institute, Cary, N.C.). The Gompertz equation is defined as:

$$
Y=a \exp [-\exp (b-k X)]
$$

where $a, b$, and $k$ are parameters. In order to comply with the Gompertz function requirement that the lower asymptote be zero, the bud viability data were rescaled to the number of bud stages terminal buds attained during the regrowth period relative to their starting bud stage at the time of sampling. For the same reason, 2-d leaf evaluation scores were subtracted from 10 (the maximum score). From each sample date, leaf data (2-d and 2week, respectively) from the most fully tested bud stages were pooled for curve fitting.

Relative freezing stress resistance (RFSR) is expressed as the $\mathrm{LT}_{50}$. These values were estimated from computer simulated curves of the Gompertz function fitted to the bud and leaf data. Bud injury levels $\left(\mathrm{LT}_{50}\right)$ were expressed as the temperatures at which the mean potential regrowth capability was impaired by $50 \%$, as compared with the unfrozen controls. Therefore, a bud $\mathrm{LT}_{50}$ corresponds to the temperature at which the regrowth capacity was impaired to half the level reached by the controls (Fig. 2). In leaves, the $\mathrm{LT}_{50}$ is the temperature at which $50 \%$ injury (2-d evaluation) or survival (2-week evaluation) was modeled to occur. $\mathrm{T}_{\max }$ was defined as the temperature at which the rate of injury or impairment to a tissue was the greatest and is determined by identifying the temperature at which the greatest value of the first derivative occurs (Fig. 2).

To obtain an expression of the variability inherent in the data comprising each curve (i.e., for each bud stage tested within each sample date), a bootstrapping method similar to von Fircks and Verwijst (1993) was applied. An SAS program was composed to sample with replacement from the original set of values at each test temperature $(n=27)$ to compile a new set of values for each test temperature $\left(\mathrm{n}_{\mathrm{i}}=27\right)$. Anew set of Gompertz parameters $(a, b$, and $k$, as described above) was then generated from this new data set. This resampling and regression procedure was repeated 100 times for each bud stage and sample date combination. A second SAS program was written to calculate $\mathrm{LT}_{50}, \mathrm{LT}_{20}, \mathrm{LT}_{10}$, and $\mathrm{T}_{\max }$ values for each of the one hundred curves $\left(\mathrm{LT}_{20}\right.$ and $\mathrm{LT}_{10}$ values not presented here). These estimates were then summarized as means and standard errors.

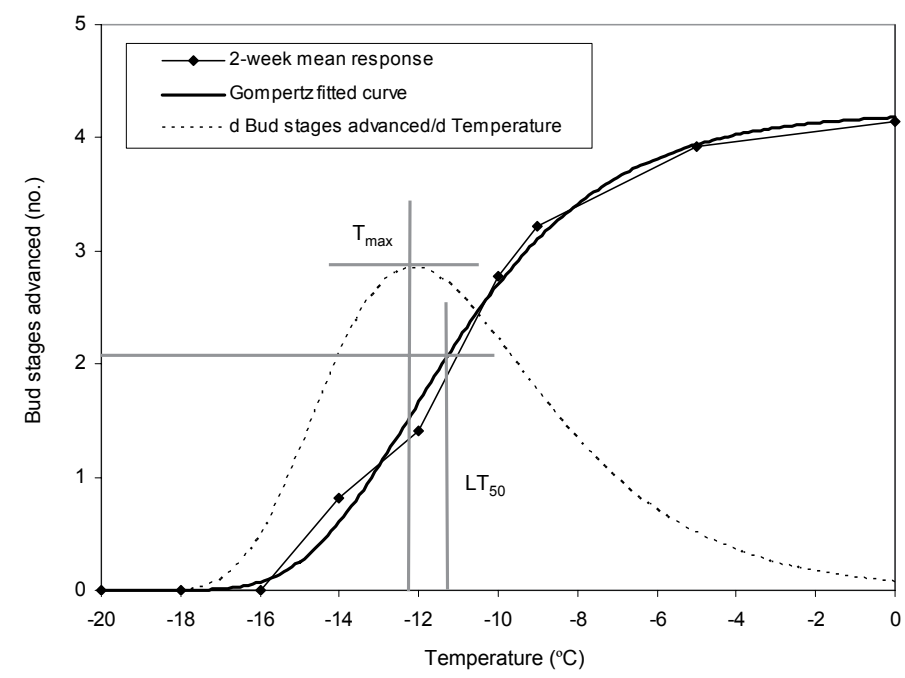

Fig. 2. Example curve from nonlinear regression method using the Gompertz function for the estimation of cranberry bud frost hardiness. Freezing stress resistance was estimated by examining the ability of buds to grow after exposure to freeze-thaw stress (results for swollen bud stage shown here). Ability of the bud to grow is expressed as the number of bud stages (as illustrated in Fig. 1) a given bud ( $n=27$ at each test temperature) was able to advance during the 2-week post-thaw period. The $\mathrm{LT}_{50}$ is the temperature at which bud growth is impaired $50 \%$, as compared to controls. The temperature at which the fastest rate of impairment occurred $\left(\mathrm{T}_{\max }\right)$ is determined by taking the first derivative of the curve (d Bud stages advanced/d Temperature). 
Climate data collection. Canopy and soil temperatures were monitored at the site (lat. $44^{\circ} 19^{\prime} 30^{\prime \prime} \mathrm{N}$, long. 89 $54^{\prime} 50^{\prime \prime} \mathrm{W}$ ) using a datalogger (model CR-10; Campbell Scientific, Logan, Utah) equipped with thermocouple sensors. Sensors were placed at the top of the canopy (height adjusted as length of new growth warranted) and were shielded to avoid direct radiation. Soil temperatures were recorded at a depth of $5 \mathrm{~cm}$, within the cranberry plant's root zone. Temperatures were logged at 10 (1997) and 20 (1998) min intervals, and later summarized into hourly and daily averages.

\section{Results}

Crop phenology. Table 1 depicts the changes in cranberry phenology over the spring seasons of 1997. Buds showed signs of swelling around 5 May. A marked increase in the percentage of swollen buds occurred by 20 and 26 May. Cabbage-headstage buds constituted over $10 \%$ of the samples by 28 May, and roughneck stage buds were present at levels $>10 \%$ by the end of the first week in June (Table 1). The timing of spring warming differed greatly between 1997 and 1998 (Fig. 3). The spring of 1998 was an exceptionally early spring in central Wisconsin, as in many parts of North America. During Winter 1997-98, ice formation over the beds was not as thick or as uniform as most years, and ice melted from the beds early following the relatively warm winter. Unseasonably warm air temperatures continued throughout the spring, although the daily average air (canopy-level) and soil temperatures from the 2 years were similar by early June. Phenological change occurred earlier and more rapidly in 1998 than in 1997. Not including the period before bud movement was noted, roughneck, early-hook, and hook stages lasted noticeably longer than the previous stages in both years (Table 1).

Terminal bUd RFSR ( LT $_{50}$ ) ESTIMATION. Regrowth ability of cranberry terminal buds was negatively impacted by decreasing temperature (Fig. 4). The pattern of mean bud regrowth in response to freezing temperatures changed over the course of each spring (Fig. 5). In the earliest samples, there was no discernible pattern of regrowth response over the range of test temperatures (Fig. 5A). Freezing stress had very little effect on the regrowth response of terminal buds collected at the beginning of the sampling period. Although the regrowth response in undamaged buds was still relatively low in controls (advancement of only about two bud stages) in early spring samples, damaging temperatures were reached (Fig. 5B). A sigmoidal response pattern was established when buds were swollen (Fig. 5C-E) and gradually this pattern shifted to relatively warmer temperatures, both within some bud stages (Fig. 5C-E) and across bud stages (Fig. 5E-G).

$\mathrm{LT}_{50}$ values were determined to estimate RFSR for terminal buds (Table 2). RFSR of cranberry terminal buds shifted markedly over the spring seasons of 1997 and 1998. No damage was observed initially in tight buds within the range of test temperatures used $\left(0\right.$ to $\left.-22^{\circ} \mathrm{C}\right)$. The first evidence of impaired bud regrowth in 1997 was recorded in swollen buds from the 5 May sample $\left(\mathrm{LT}_{20}\right.$ and $\mathrm{LT}_{10}$ estimations, data not shown). After this date, it was possible to estimate RFSR values for all tested bud stages, provided the range of test temperatures was adequate. On 9 and 24 May, swollen buds were estimated to be hardier than tight buds. Between these two dates, the hardiness values from both stages fluctuated similarly. From 26 May until the end of the sampling period, the $\mathrm{LT}_{50}$ values (Table 2) showed better separation between the bud stages than the $\mathrm{LT}_{20}$ or $\mathrm{LT}_{10}$ (data not shown). Swollen buds gradually lost hardiness up to the beginning of June (Table

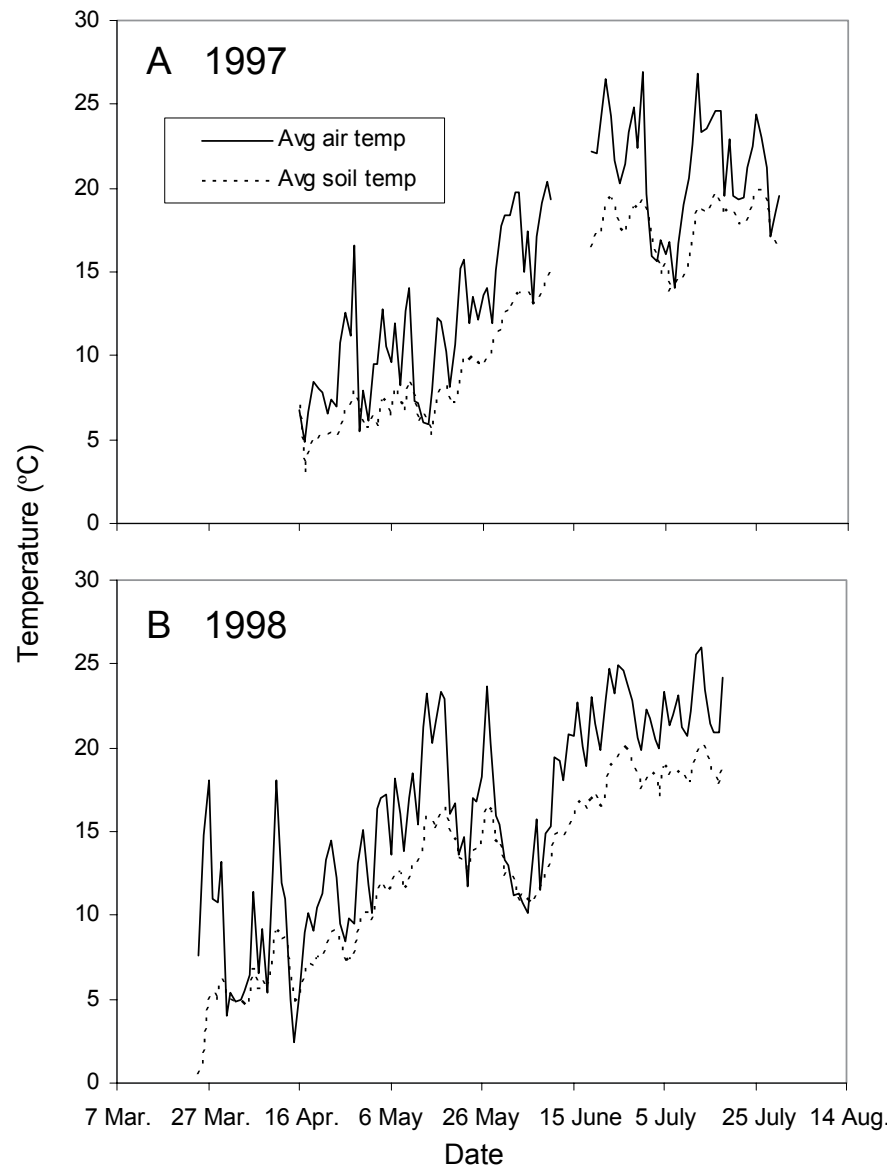

Fig. 3. Average canopy-level air and soil $(5 \mathrm{~cm}$ below surface) temperatures recorded in a cranberry bed at Nekoosa, Wis. in Spring 1997 and 1998. Temperatures were measured with shielded copper-constantan thermocouples and recorded at 10 (1997) and 20 (1998) min intervals, using a datalogger (model CR-10; Campbell Scientific, Logan, Utah).

2). Buds at cabbage-head and budbreak stages were relatively less hardy than swollen and tight buds (Table 2). Uprights at the stages of bud elongation, roughneck, and early-hook were the most sensitive to freezing temperatures.

In 1998, bud RFSR values followed a trend similar to that of 1997. Comparison between LT $_{50}$ estimates for 1997 and 1998 (based on crop phenology) shows similar shifts in bud hardiness values with changes in bud development, although 1997 estimates were generally lower (Table 3 ).

A plot of the terminal bud $\mathrm{LT}_{50}$ values vs. the $\mathrm{T}_{\max }$ values (Fig. 6) shows that for nearly all sample dates and starting bud stage combinations, the $\mathrm{T}_{\max }$ occurs at a temperature lower than the $\mathrm{LT}_{50}$. This indicates that the simulated sigmoid curves are asymmetric, with the highest rate of growth impairment occurring at temperatures colder than where the mean growth potential of the buds is compromised to half of its potential.

LEAF CRITICAL TEMPERATURES. $\mathrm{LT}_{50}$ values were determined to estimate RFSR for previous year leaves, based on evaluations at both $2 \mathrm{~d}$ and 2 weeks after the application of freezing stress (Table 4). Leaf critical temperature values changed gradually over the course of the spring. Evaluation at 2 weeks (Table 4) showed a trend of decreasing hardiness, similar to buds, although the initial loss of hardiness was more gradual in the leaves over time, and more stochastic in the buds. Leaf hardiness changed concomitantly with bud hardiness, although leaf levels were generally 1 to $2{ }^{\circ} \mathrm{C}$ 


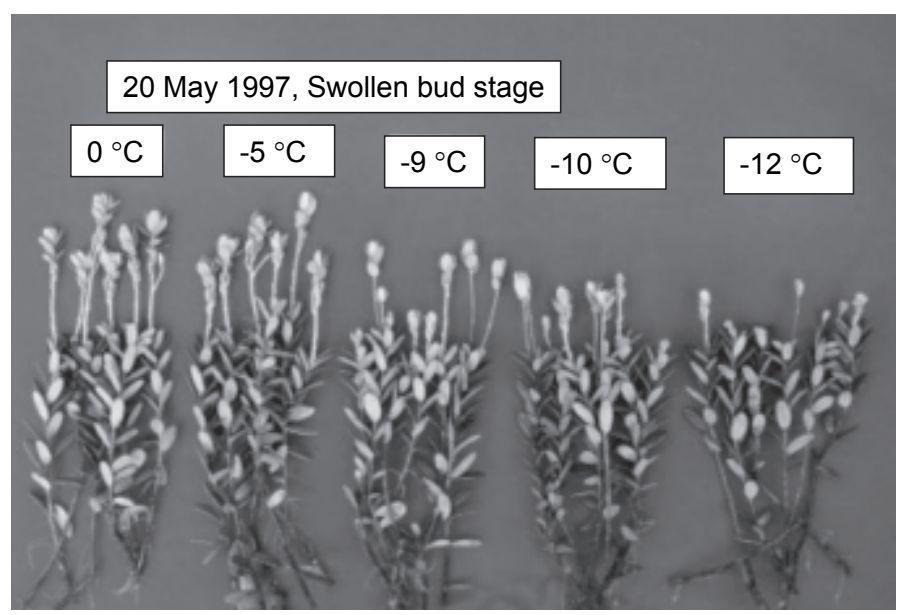

Fig. 4. Example of the effect of freezing temperatures on 'Stevens' cranberry terminal bud regrowth ability (swollen buds sampled on 20 May 1997). Following controlled freezing tests to various temperatures, uprights were placed in 70$\mathrm{mL}$ test tubes under fluorescent lights at room temperature for 2 weeks before evaluation of regrowth ability.
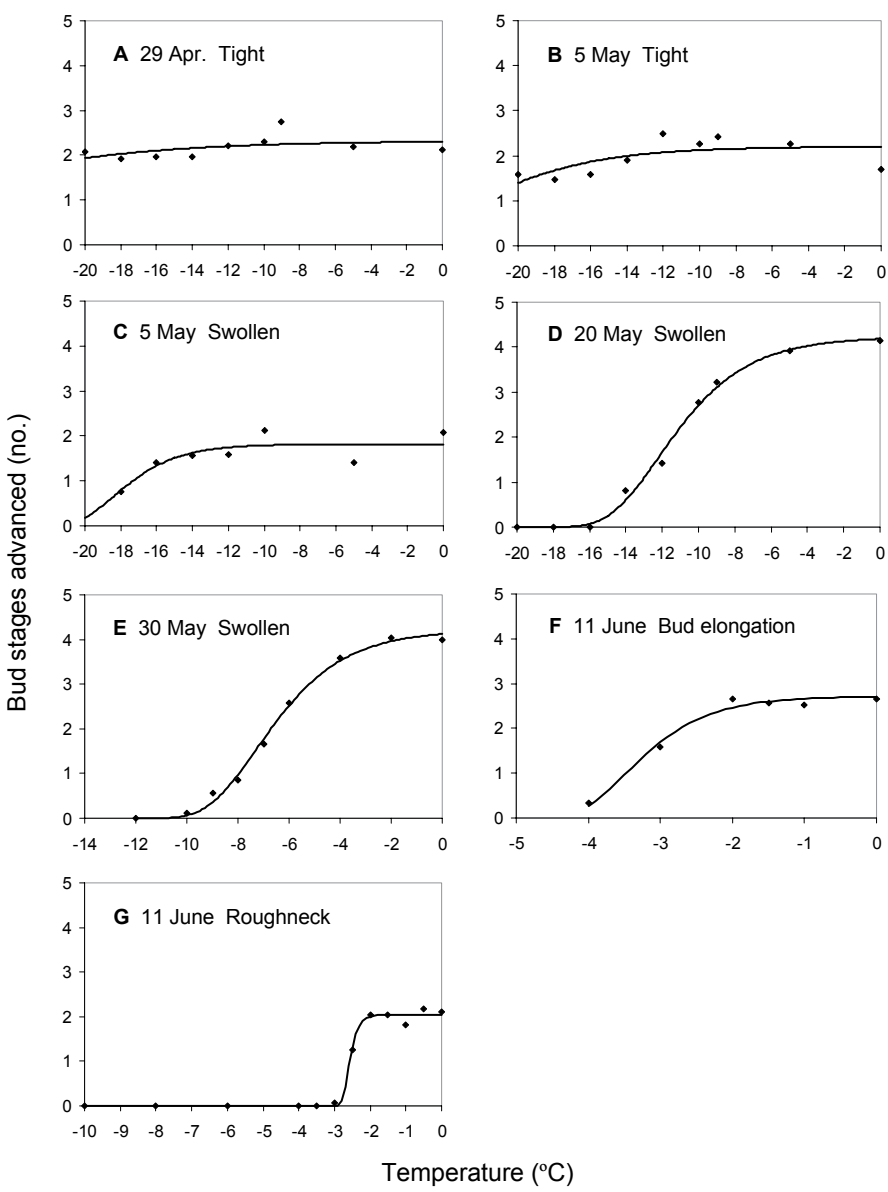

Fig. 5. Plots of mean cranberry bud regrowth in response to freezing temperatures. Plots illustrate advances in bud stages relative to the starting stage at the time of sampling, as a function of temperature. Observations were made after buds were allowed to grow for 2 weeks at room temperature following controlled freezing tests $(\mathrm{n}=27$ at each test temperature). Starting bud stages at the time of the freezing tests were: (A) 29 Apr., tight; (B) 5 May, tight; (C) 5 May, swollen; (D) 20 May, swollen; (E) 30 May, swollen; (F) 11 June, bud elongation; and (G) 11 June, roughneck. Fitted curves were determined by the Gompertz function.
Table 3. Comparison of cranberry terminal bud $\mathrm{LT}_{50}$ estimates from controlled freezing tests for Spring 1997 and 1998. LT $_{50}$ is the temperature at which bud growth is impaired $50 \%$, as compared to controls. Estimates are means of multiple runs $(n=100)$ of the freezing stress response curve ( $n=27$ at each test temperature) using the Gompertz function with a bootstrapping with replacement method. Date comparisons from year to year based on bud stage phenology.

\begin{tabular}{|c|c|c|c|c|c|}
\hline \multicolumn{3}{|c|}{1997} & \multicolumn{3}{|c|}{1998} \\
\hline Date & Stage $^{z}$ & $\mathrm{LT}_{50}\left({ }^{\circ} \mathrm{C}\right)$ & Date & Stagez $^{2}$ & $\mathrm{LT}_{50}\left({ }^{\circ} \mathrm{C}\right)$ \\
\hline 15 Apr. & $\mathrm{T}(100)$ & $<-22.0$ & 6 Apr. & $\mathrm{T}(100)$ & -23.6 \\
\hline 22 Apr. & $\mathrm{T}(100)$ & $<-22.0$ & & & \\
\hline 27 Apr. & $\mathrm{T}(100)$ & $<-20.0$ & & & \\
\hline 29 Apr. & $\mathrm{T}(100)$ & $<-22.0$ & & & \\
\hline 2 May & $\mathrm{T}(100)$ & $<-22.0$ & & & \\
\hline 5 May & $\mathrm{T}(88)$ & $<-20.0$ & 27 Apr. & $\mathrm{T}(85)$ & -15.0 \\
\hline 9 May & $\mathrm{T}(90)$ & -13.1 & & & \\
\hline 13 May & $\mathrm{T}(83)$ & -14.9 & & & \\
\hline 16 May & $\mathrm{T}(83)$ & -16.3 & 4 May & $\mathrm{T}(80)$ & -10.7 \\
\hline 20 May & $\mathrm{T}(60)$ & -13.0 & & & \\
\hline 5 May & SW(12) & -18.2 & 27 May & SW(15) & -18.6 \\
\hline 9 May & SW(10) & -13.9 & & & \\
\hline 13 May & SW(18) & -11.2 & & & \\
\hline 16 May & SW(17) & -14.1 & 4 May & SW(20) & -13.5 \\
\hline 20 May & SW(40) & -11.2 & & & \\
\hline 26 May & SW(64) & -8.6 & 7 May & SW(64) & -6.0 \\
\hline 3 June & $\mathrm{CH}(24)$ & -5.5 & 14 May & $\mathrm{CH}(23)$ & -4.1 \\
\hline 3 June & BB(29) & -4.6 & 14 May & $\mathrm{BB}(34)$ & -3.4 \\
\hline
\end{tabular}

zT = tight, $\mathrm{SW}=$ swollen, $\mathrm{CH}=$ cabbage-head, $\mathrm{BB}=$ budbreak. Phenology values (shown in parentheses) are the percentage of a given bud stage present at sampling time.

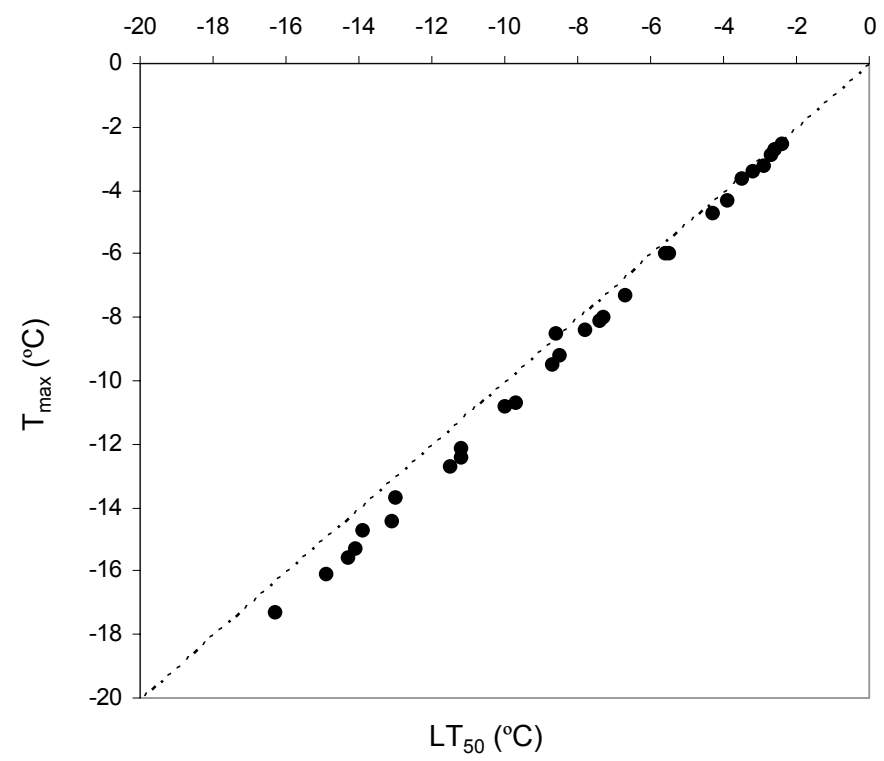

Fig. 6. Plot of cranberry upright terminal bud $\mathrm{LT}_{50}$ values versus terminal bud $\mathrm{T}_{\mathrm{m}}$ values from Spring 1997. The $\mathrm{LT}_{50}$ is the temperature at which bud growth is impaired $50 \%$, as compared to controls, determined by nonlinear curve fitting using the Gompertz function. $\mathrm{T}_{\text {mx }}$ is the temperature at which the fastest rate of impairment occurred and is determined by taking the first derivative of the fitted curve. The dotted line depicts the relationship if $\mathrm{LT}_{50}$ equaled $\mathrm{T}_{\max }$. 
Table 4. Estimated $\mathrm{LT}_{50}$ values based on watersoaking (2-d) and survival (2-week) evaluation values for previous year cranberry leaves sampled during Spring 1997. $\mathrm{LT}_{50}$ is the temperature at which 50\% injury (2-d evaluation) or survival (2-week evaluation) was modeled to occur. Estimates are means of multiple runs $(n=100)$ of the freezing stress response curve using the Gompertz function. A bootstrapping with replacement method was used to generate new data sets at each test temperature. Values given with a < sign are the lowest test temperature on that date for the stage given, which was not cold enough to yield a sufficient response curve.

\begin{tabular}{lcc}
\hline & \multicolumn{2}{c}{$\mathrm{LT}_{50}\left[\mathrm{mean} \pm \mathrm{SE}\left({ }^{\circ} \mathrm{C}\right)\right]$ as estimated by } \\
\cline { 2 - 3 } Date & Watersoaking $(2 \mathrm{~d})$ & Survival $(2$ weeks $)$ \\
\hline 15 Apr. & $-19.1 \pm 0.02$ & $\leq-22$ \\
22 Apr. & $-19.0 \pm 0.04$ & $\leq-22$ \\
27 Apr. & $-19.0 \pm 0.04$ & $-21.6 \pm 0.02$ \\
29 Apr. & $-17.3 \pm 0.02$ & $-20.0 \pm 0.06$ \\
2 May & $-16.0 \pm 0.01$ & $-18.5 \pm 0.01$ \\
5 May & $-16.8 \pm 0.02$ & $-15.6 \pm 0.02$ \\
9 May & $-15.3 \pm 0.01$ & $-15.4 \pm 0.02$ \\
13 May & $-15.2 \pm 0.02$ & $-17.0 \pm 0.02$ \\
16 May & $-15.2 \pm 0.02$ & $-13.7 \pm 0.02$ \\
20 May & $-12.8 \pm 0.01$ & $-13.7 \pm 0.02$ \\
22 May & $-12.9 \pm 0.01$ & $-10.3 \pm 0.01$ \\
24 May & $-9.5 \pm 0.01$ & $-10.6 \pm 0.02$ \\
26 May & $-9.3 \pm 0.01$ & $-9.4 \pm 0.02$ \\
28 May & $-8.8 \pm 0.01$ & $-7.3 \pm 0.01$ \\
30 May & $-7.6 \pm 0.01$ & $-7.5 \pm 0.01$ \\
1 June & $-8.1 \pm 0.02$ & $-7.9 \pm 0.02$ \\
3 June & $-7.9 \pm 0.01$ & $-7.4 \pm 0.01$ \\
5 June & $-7.5 \pm 0.01$ & $-6.6 \pm 0.02$ \\
11 June & $-6.9 \pm 0.02$ & $-4.9 \pm 0.02$ \\
18 June & $-5.6 \pm 0.01$ & $-5.1 \pm 0.03$ \\
25 June & $-5.0 \pm 0.01$ & \\
\hline
\end{tabular}
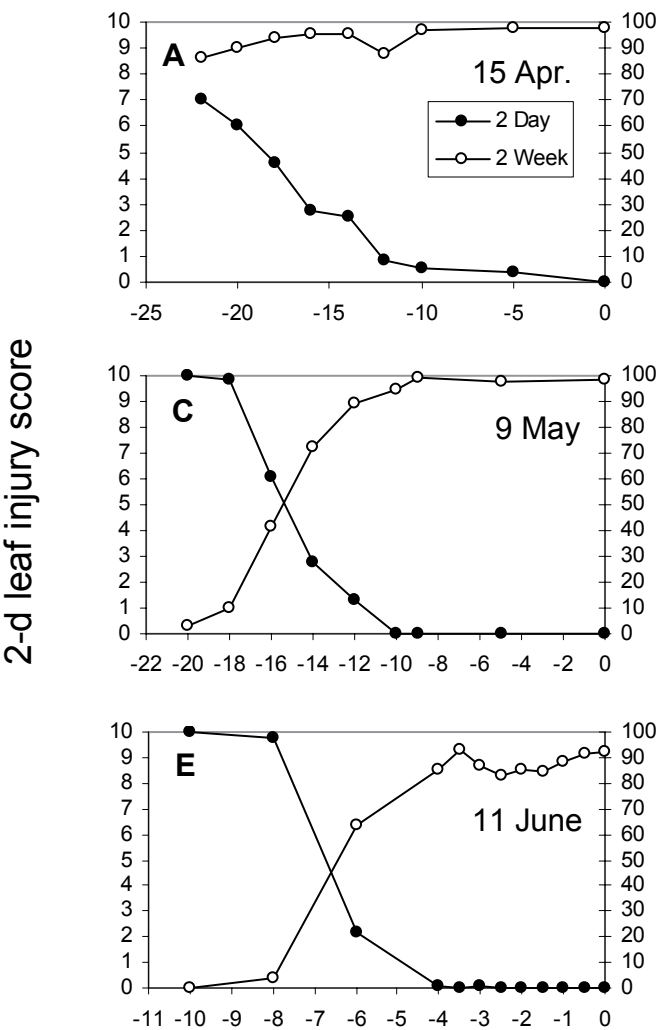

hardier than the leading bud stage at a given sample date. $\mathrm{LT}_{50}$ determinations from 2-d leaf injury scores and 2-week survival scores did not correspond early in the season (Fig. 7). In early spring, symptoms of moderate to severe injury were noted at the 2-d evaluations (Fig. 7 A and B), although these same leaves had high levels of survival after 2 weeks. Injury and survival did correspond at subsequent dates (Fig. 7C-E).

Air temperatures and COLD HaRdiness. Canopy-level air temperatures corresponded with the pattern of changing hardiness levels for each year (Fig. 8). In 1997, there was a prolonged period (the first 3 weeks in May) where the minimum air temperature was often at or near $0{ }^{\circ} \mathrm{C}$. This occurred either naturally or was maintained during nights of frost protection. During this time, the tight and swollen bud hardiness values fluctuated in response to air temperature changes, although these hardiness values remained clustered in the negative mid-teens degrees Celsius. In contrast, there was only a brief period in 1998 during which minimum air temperatures were around $0{ }^{\circ} \mathrm{C}$. The tight bud hardiness value from this time $\left(-15.0{ }^{\circ} \mathrm{C}\right.$ on 25 April) was comparable to those values from 1997. Later, as minimum air temperatures rose and fluctuated above and below $5^{\circ} \mathrm{C}$, tight bud hardiness decreased to around -8 to $-10{ }^{\circ} \mathrm{C}$ for both years (Fig. 8). In both years, the minimum soil temperature did not correspond with the early bud hardiness changes and fluctuations, although a shift to warmer soil temperatures (around 26 May 1997 and 4 May 1998) did coincide with bud sensitivity reaching to $-5^{\circ} \mathrm{C}$ and greater (Fig. 8).

Fig. 7. (below) Cranberry leaf injury scores (2-d evaluations) and percentage leaf survival (2-week evaluations) from Spring 1997 following controlled freezing tests on plant uprights ( $\mathrm{n}=54$ at each test temperature): (A) 15 Apr., (B) 29 Apr., (C) 9 May, (D) 20 May, and (E) 11 June. Watersoaking and darkening was scored (1 to 10 scale) for the 2 -d evaluation. The percentage of retention of green healthy leaves on each upright was used for the 2-week evaluation.
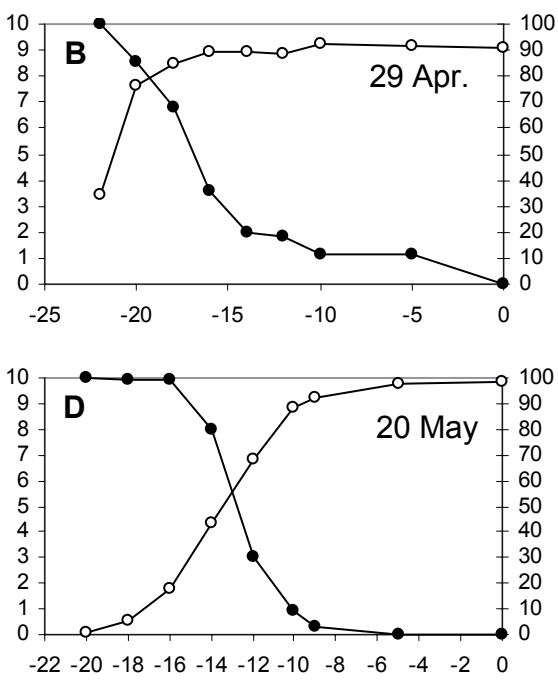

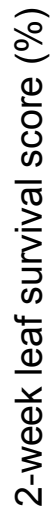

Temperature $\left({ }^{\circ} \mathrm{C}\right)$ 

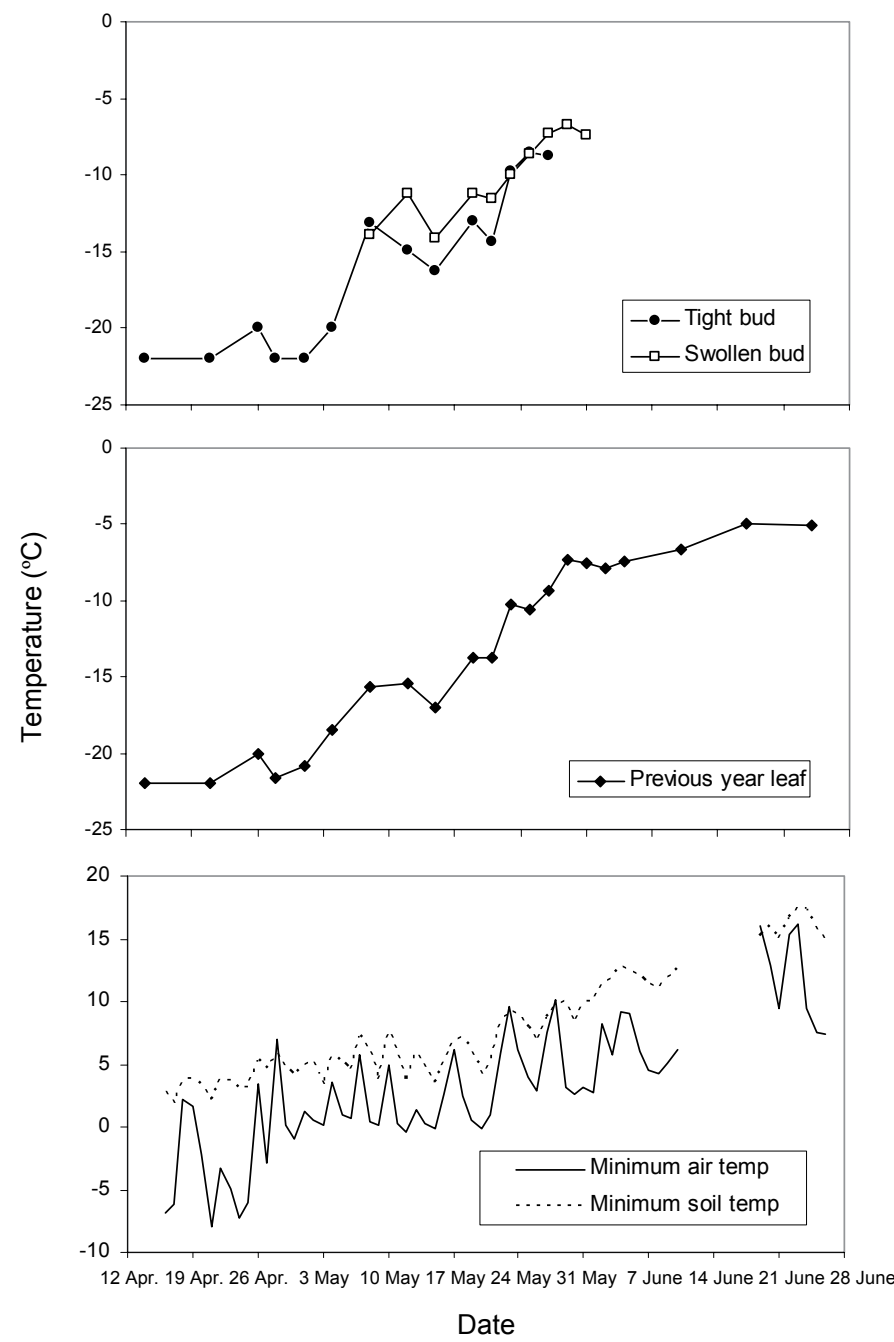

Fig. 8. Changes in cranberry terminal bud (A) and previous year leaf (2-week evaluation) (B) $\mathrm{LT}_{50}$ values in relation to daily minimum canopy-level air and minimum soil ( $5 \mathrm{~cm}$ below surface) temperatures (C) in Spring 1997. Terminal buds were tested at the tight and swollen stages. The $\mathrm{LT}_{50}$ is the temperature at which bud growth is impaired $50 \%$, as compared to controls, determined by nonlinear curve fitting using the Gompertz function. $\mathrm{LT}_{50}$ for leaves is the temperature at which $50 \%$ survival of the leaves occurred. Temperatures were measured with shielded copper-constantan thermocouples and recorded at 10-min (1997) and 20-min (1998), using a datalogger (model CR-10; Campbell Scientific, Logan, Utah). The gap in temperatures was due to technical difficulties.

\section{Discussion}

This study provides precise estimates of changes in cranberry terminal bud and leaf freezing stress resistance in spring. This was achieved by systematically testing leading bud stages from the field and utilizing a nonlinear regression analysis based on the relative scoring of post-freeze-thaw bud growth and development and leaf survival. Such a systematic study has not been reported on cranberry before. We found a substantial change in cranberry bud freezing stress resistance (less than $-22{ }^{\circ} \mathrm{C}$ to about $-1{ }^{\circ} \mathrm{C}$ ) during development. By evaluating several leading bud stages, we were able to demonstrate that freezing stress resistance changes occurred even within the same bud stage as soil and air temperatures increased during spring (Tables 2 and 3 , Fig. 8). Furthermore, our results show that most dramatic losses in freezing stress resistance occurred both within and between the tight and swollen bud stages. These results demonstrate that hardiness changes in buds during spring are both dependent and independent of changes in bud morphology.

Controlled freezing experiments on cranberry plant material have varied in focus and methods. Attempts to relate freezing stress resistance to spring developmental stages have been reported for cranberries grown in Massachusetts (DeMoranville, 1998; DeMoranville and DeMoranville, 1997; Roberts and DeMoranville, 1985). DeMoranville and DeMoranville (1997) studied changes in cranberry bud hardiness during spring development. Using potted sods in controlled temperature chambers, they observed differences between both developmental stages and cultivars. From spring dormant to bloom, shifts in hardiness were defined from $15{ }^{\circ} \mathrm{F}$ (about $-9{ }^{\circ} \mathrm{C}$ ) to $30^{\circ} \mathrm{F}$ (about $-1{ }^{\circ} \mathrm{C}$ ), respectively. These changes are not as dramatic as we found in our study. Ice nucleation was not controlled in these experiments, thus increasing the potential for these plants to supercool. In addition, the volume of sod present in the chamber may have created a lag in the cooling rates of the chambers and an uneven distribution of temperatures. In our study we initiated ice nucleation at $-1{ }^{\circ} \mathrm{C}$ and subjected individual uprights to freeze-thaw stress.

Using controlled freezing tests in a circulating bath with ice nucleation at $-1{ }^{\circ} \mathrm{C}$, Abdallah (1989) documented seasonal changes in freezing stress resistance of different plant parts (leaf, bud, flower, and fruit), but did not distinguish between uprights of different stages of development. In this study, leaves and terminal buds were shown to behave like many temperate zone plants by having a dramatic gain in freezing stress resistance during cold acclimation in the fall, followed by a quick loss in the spring. Eaton and Mahrt (1977) performed the only known differential thermal analysis on cranberry terminal buds. However, they used excessively rapid cooling rates $\left(1{ }^{\circ} \mathrm{C} / \mathrm{min}\right.$ for freezing tests and $20{ }^{\circ} \mathrm{C} / \mathrm{min}$ for low temperature exotherm analysis), making their findings unreliable for practical use. It has been shown that excessively rapid cooling rates typically cause low temperature exotherms to occur at relatively warmer temperatures (Quamme, $1995)$ These rates of cooling do not typically occur in nature and are not recommended for in vivo measurement of plant freezing stress resistance (Steffen et al., 1989).

Changes IN TERMINAL BUD HARDINESS RELATED TO MORPHOLOGY. Phenological development is considered to be the most important factor contributing to the hardiness of woody plant buds in spring (Rodrigo, 2000). We found that change in the cranberry terminal bud morphology is one of the major factors related to the changes in the spring RFSR (Table 2). This was especially true as the buds advanced to the cabbage-head stage. The effects of freezing temperatures on cranberry bud regrowth (Fig. 4) were similar to those found by Spiers (1978) on rabbiteye blueberry, where the regrowth of floral buds at a given stage of development was increasingly compromised with decreases in temperature. In our study, swollen buds were expected to be less hardy than co-occurring tight buds because of the assumption that morphological changes of the bud are related to internal anatomical changes (Ashworth et al., 1992). Especially as buds begin to swell, it is assumed that a xylem connection to the dormant bud has been established, to supply water. This was found to be true, with an exception in 1998, where for two dates swollen buds had a lower RFSR than did tight buds (Tables 2 and 3).

In a summary of the low temperature resistance of the developing flower buds of six deciduous fruit species (apple, pear, sweet cherry, peach, apricot, and prune), Proebsting and Mills (1978) observed that the critical temperature $\mathrm{T}_{50}[\mathrm{sic}]$ rose rapidly with signs of visible swelling in the buds. In addition, the range between 
the $\mathrm{T}_{90}$ and $\mathrm{T}_{10}$ became smaller. Concord grape buds also showed a loss of hardiness with phenological change, but the transition as the buds developed was not abrupt between stages (Johnson and Howell, 1981a).

CHANGES IN TERMINAL BUD HARDINESS UNRELATED TO MORPHOLOGY. In our study, differences of up to $3^{\circ} \mathrm{C}$ in the $\mathrm{LT}_{50}$ values were determined between tight and swollen buds, as well as between swollen and cabbage-head buds (Table 2). The largest changes in RFSR occurred within the tight and swollen bud stages (e.g., more than a $7{ }^{\circ} \mathrm{C}$ change in tight buds from 5 to 9 May 1997), while the differences between bud stages were not as great (Table $2)$. These results clearly show that seasonal changes in freezing stress resistance do not necessarily parallel changes in crop phenology and bud development. The explanation for these changes perhaps lies in the changes in the anatomical, physiological, and biochemical parameters that are distinct from morphology.

The development of primary xylem into the floral organs of a bud has been related to a loss in the ability of the bud to supercool (Ashworth, 1982, 1984, 1990; Ashworth etal., 1992). In cranberry terminal buds, if vascular differentiation and other anatomical changes occur in tight buds before any morphological changes in the bud are detectable, buds would be increasingly vulnerable to internal sources of ice. With further development, the bud scales loosen and the bud contents would be more susceptible to extrinsic ice penetration. In addition to these anatomical changes, some biochemical changes, such as membrane lipids, may help explain changes in hardiness that are not associated with morphology (Palta et al., 1993).

Comparisons of 1997 AND 1998 HARdiness. It is often not possible or is impractical to repeat woody plant cold hardiness experiments within one season, especially when seasonal changes are being investigated, requiring sampling over a period of time. Each sampling date is unique. To compare year to year, some common feature, either morphological or physiological, must be identified. In our study, collected uprights were sorted by bud stage (Fig. 1), giving a phenological profile of the progress of growth and development of the population on each date (Table 1). Similar points in the crops' phenologies were chosen from each year as the basis for both the comparison of bud growth potential in the unfrozen controls (data not shown), and hardiness estimations for terminal buds (Table 3). These phenology points did not always match exactly, but were generally comparable. Although the absolute RFSR values were different between the years, the magnitudes of the hardiness shifts were comparable in the 2 years of the study (Table 3 ). Differences in the determined hardiness may be attributed to the acclimation status of the plants, a phenomenon most directly related to the recent experience of temperature.

Leaf haRdiness estimation. Previous year leaves were able to initially attain hardiness levels comparable to that of tight terminal buds (compare $\mathrm{LT}_{50}$ estimates in Tables 2 and 4). Buds from advanced stages were typically less hardy than previous year leaves. Early in the season there were discrepancies in the RFSR estimations based on the 2-d and 2-week evaluations (Fig. 7), where leaves from the lowest test temperatures showed substantial visible signs of injury after $2 \mathrm{~d}$, yet had fairly high levels of survival after 2 weeks. As previous year leaves became more sensitive, better correspondence was obtained between the two sets of evaluation data. This may indicate that, in the initial weeks after ice-off, previous year leaves may possess the ability to recover from freeze-induced injury. However, assessment of watersoaking in the thick waxy leaves of cranberry can often be challenging. Similarly, in preliminary studies interpretation of ion leakage data from previous year leaves was problematic, similar to the work on red pine (Pinus resinosa Ait.) needles by Sutinen et al. (1992). Even at severely damaging temperatures, contents from injured cells become trapped in the thick suberized tissue, resulting in very low leakage (relative to the autoclaved values). This phenomenon makes the visual observation of watersoaking difficult, as well. As a result, leaf survival was found to be the most reliable indicator of hardiness.

SOURCES OF IMPAIRMENT TO GROWTH AND DEVELOPMENT. One source of plant growth and development impairment is the disruption of basic cellular functions, such as photosynthesis and respiration. The photosynthetic ability of plant tissue can be impaired by temperature stress, sometimes with the possibility of recovery (Rutten and Santarius, 1992; Steffen et al., 1989; Tewari and Tripathy, 1998). Steps in the chlorophyll biosynthesis pathway (Tewari and Tripathy, 1998) and Photosystem II-mediated electron transport (Rutten and Santarius, 1992) are some of the vulnerable processes. Steffen et al. (1989) found that net photosynthesis was much more sensitive to increasing freezing stress than was respiration in two wild potato species (Solanum acaule Bitt. and S. commersonii Dun.). In cranberry, previous year leaves may provide photoassimilates to early growth (Hagidimitriou and Roper, 1995), and such impairment of the photosynthetic apparatus in early spring could compromise initial growth of the upright.

Another source of impairment to plant growth and development as a result of freezing stress is xylem cavitation (Sperry and Dobson, 2001). Air bubbles that form as xylem water freezes can expand to cause cavitation during or after thawing if xylem pressures are low enough. Extensive cavitation reduces the hydraulic conductance of the xylem, resulting in water stress. Species with smaller conduit diameters $(<30 \mu \mathrm{m})$ resist cavitation caused by freezing (Davis et al., 1999). To our knowledge, cranberry xylem vessel diameter measurements have not been reported. If the freezing front advances fast enough $\left(>75 \mu \mathrm{m} \cdot \mathrm{s}^{-1}\right)$, gas molecules will not be able to diffuse out of the water, but instead will be trapped in the crystal lattice structure of the ice, with no bubble formation (Robson et al., 1988; Robson and Petty, 1987; Sperry and Dobson, 2001). Ice front movement in cranberry upright stems has been recently measured by infrared video thermography at a rate of $1.2 \mathrm{~cm} \cdot \mathrm{s}^{-1}$ (Workmaster et al., 1999). In theory, it is unlikely that air bubble formation occurs in cranberry xylem during freezing.

Additionally in our study, the bud axis area (the area subtending the location of bud scale attachment) of bisected buds often appeared darkened or brown while the vegetative and reproductive structures inside the bud remained green or had turned pale green or yellow. This type of injury could contribute to the impairment of the bud's potential to grow by inhibiting water uptake. The structure of the bud axis area has been identified as having a potential role in the ability of the dormant peach floral bud to supercool (Quamme et al., 1995). In this region, the composition of the cell walls may act as a physical barrier to the propagation of ice to dormant buds, but contribute to the vulnerability of this area once spring growth and development have been initiated.

AIR AND SOIL TEMPERATURE EFFECTS ON BUd AND LEAF RFSR. Many of the differences seen between the terminal bud and previous year leaves hardiness estimations may be attributable to the influence of ambient temperatures. The RFSR levels of both tight and swollen buds and previous year leaves changed in relation to canopy-level air temperatures (Fig. 8). A shift in 
phenology and hardiness coincided with a rise in the minimum canopy-level air temperature to above freezing. Similar patterns of freezing stress resistance fluctuations have also been shown in deciduous fruit species (Proebsting, 1963, 1970). Spring warming occurred much earlier in 1998 than in 1997 (Fig. 3), which did have an effect on the timing of deacclimation of previous year leaves. Changes in the soil temperature $(5 \mathrm{~cm}$ below surface) did not appear to influence the phenology or RFSR of buds and previous year leaves.

NONLINEAR REGRESSION AND RESAMPLING TECHNIQUE. Nonlinear regression methods have been used to characterize continuums of plant growth and plant response (Causton and Venus, 1981). When curve-fitting methods are used with freezing stress response data, all of the test temperature data points contribute to the shape of the sigmoidal dose response to freezing stress, thereby smoothing out the vagaries between test temperatures. Although conventional freezing stress resistance estimates are influenced by the upper and lower asymptotes, these studies actually rely on interpolation between two test temperature response values for a critical temperature estimation, such as $\mathrm{LT}_{50}$ (Sutinen et al., 1992).

Although all of the data points comprising the freezing stress dose-response contribute to the shape of the fitted curve, it is not always possible, or practical, to obtain complete curves when testing woody plant material. The limits of testing equipment may not reach temperatures cold enough to induce complete killing damage. This often occurs with the testing of acclimated tissues (Anisko and Lindstrom, 1995; Zatlyny et al., 1996). In our study, such incomplete curves were obtained for both terminal buds and previous year leaves (Figs. 5 and 7). Nonlinear regression experts warn against applying a more complex curve to a data set than is warranted, as well as extrapolating beyond the limit of a data set (Ratkowsky, 1990). An incomplete freezing stress response curve may appear to warrant a simpler function for curve-fitting, but since this biological response is known to be sigmoidal (Zhu and Liu, 1987), we feel the application of such a function is justified. Thus, the most important issue becomes having enough of the curve to be able to 1 ) estimate the desired critical temperature levels; and 2) reduce the variability between multiple runs of the curve fitting, if a resampling technique is employed.

In our study, data points comprising half or more of the curve were needed to estimate $\mathrm{LT}_{50}$ and $\mathrm{T}_{\max }$ values. Low standard errors (about $\leq 0.2^{\circ} \mathrm{C}$ ) resulted from the bootstrapping procedure when both a sufficient portion of the curve was present and the range of response values at each test temperature (e.g., $\mathrm{n}=27$ for terminal buds) was relatively narrow in the regions of the curve where moderate levels of damage were incurred.

In order to avoid extrapolating beyond the limits of their data, Lim et al. (1998) subjected some their Rhododendron L. leaf samples to $-80{ }^{\circ} \mathrm{C}$ (freezer) for $4-5 \mathrm{~h}$ in order to obtain data points at complete damaging levels and to complete each curve. The next warmest test temperature was $-27^{\circ} \mathrm{C}$, however, and the temperature at which complete damage may have first been possible could have been significantly warmer than -80 ${ }^{\circ} \mathrm{C}$, which may have influenced the shape of the fitted curves. In studies using electrolyte leakage data, identifying the temperature at which complete damage occurs is useful for the calculation of an index of injury by transforming the raw leakage data into an adjusted percentage. In our study, hardiness was determined by the degree of survival, rather than the degree of damage, so the upper asymptote of each curve was set by the average level of regrowth in the unfrozen control in each test. Therefore, the
$\mathrm{LT}_{50}$ estimation possible for each data set was limited only by the degree of impairment (buds) or damage (leaves) sustained.

Conclusions. Our study provides precise estimates of the cold hardiness changes in cranberry terminal buds and leaves in spring. Although general estimates of cranberry terminal bud cold hardiness exist in the literature (DeMoranville, 1998; DeMoranville and DeMoranville, 1997), this is the first study to test the leading bud stages and to relate these estimates to environmental changes (air and soil temperatures). Other work on cranberry bud hardiness did not focus on bud developmental changes, and so is only generally comparable (Abdallah, 1989; Abdallah and Palta, 1989). Our study is a first step toward understanding the changes in cranberry bud hardiness as they relate to the field environment. Furthermore, we provide important data on seasonal changes in freezing stress resistance within a bud stage, as well as on changes in freezing stress resistance with bud developmental changes during spring. We found large changes in hardiness within a bud stage, especially within tight and swollen buds. These results clearly show that seasonal changes in freezing stress resistance do not necessarily parallel changes in crop phenology and bud development. The explanation for these changes perhaps lie in the changes in the anatomical, physiological, and biochemical parameters that are distinct from morphology.

Another unique aspect of this study is the assessment of bud cold hardiness by nonlinear regression utilizing relative scoring of post-freeze-thaw bud growth and development based on defined bud stages. Although an interest in the use of faster methods of freezing stress injury evaluation, such as electrolyte leakage, chlorophyll fluorescence, and peroxide radicals, has been developed, the ultimate measure of a tissue's freezing stress resistance is its ability to survive. Rather than targeting a particular cellular process or response, regrowth assessment of the cranberry upright inherently describes the composite effects of freezing stress on plant health.

\section{Literature Cited}

Abdallah, A.Y.1989. Biochemical and biophysical parameters coinciding with initiation of fruits ripening and with seasonal changes in freezing stress resistance of the cranberry plant. PhD Diss. 8924056, Univ. of Wisconsin, Madison.

Abdallah, A.Y. and J.P. Palta. 1989. Changes in the freezing stress resistance of the cranberry leaf, flower bud, and fruit during growth and development. Acta Hort. 241:273-276.

Anisko, T. and O.M. Lindstrom. 1995. Applying the Richards function in freezing tolerance determination with electrolyte and phenolic leakage techniques. Physiol. Plant. 95:281-287.

Ashworth, E.N. 1982. Properties of peach flower buds which facilitate supercooling. Plant Physiol. 70:1475-1479.

Ashworth, E.N. 1984. Xylem development in Prunus flower buds and the relationship to deep supercooling. Plant Physiol. 74:862-865.

Ashworth, E.N. 1990. The formation and distribution of ice within forsythia flower buds. Plant Physiol. 92:718-725.

Ashworth, E.N., T.J. Willard, and S.R. Malone. 1992. The relationship between vascular differentiation and distribution of ice within forsythia flower buds. Plant Cell Environ. 15:607-612.

Causton, D.R. and J.C. Venus. 1981. The biometry of plant growth. Edward Arnold, London.

Dana, M.N. 1990. Cranberry management, p. 334-362. In: G.J. Galletta and D.G. Himelrick (eds.). Small fruit crop management. Prentice Hall, Englewood Cliffs, N.J.

Davis, S.D., J.S. Sperry, and U.G. Hacke. 1999. The relationship between xylem conduit diameter and cavitation caused by freeze-thaw events. Amer. J. Bot. 86:1367-1372. 
DeMoranville, C.J. 1998. Frost protection guide for Massachusetts cranberry production. Cranberry Expt. Sta., Univ. Mass. Ext., East Wareham, Mass.

DeMoranville, C.J. and I. DeMoranville. 1997. Cold tolerance of cranberry flower buds differs by cultivar and developmental stage. HortScience 32:537. (Abstr.)

Doughty, C.C. and A.W. Shawa. 1966. Cold injury to cranberries in 1965 in Washington. Cranberries 30:20-24.

Eaton, G.W. and B.J. Mahrt. 1977. Cold hardiness testing of cranberry flower buds. Can. J. Plant Sci. 57:461-465.

Eck, P. 1990. The American cranberry. Rutgers Univ. Press, New Brunswick, N.J.

Hagidimitriou, M. and T.R Roper. 1995. Seasonal changes in $\mathrm{CO}_{2}$ assimilation of cranberry leaves. Sci. Hort. 64:283-292.

Holt, M.A. and N.E. Pellett. 1981. Cold hardiness of leaf and stem organs of Rhododendron cultivars. J. Amer. Soc. Hort. Sci. 106:608-612.

Jánacek, J. and I. Prásil. 1991. Quantification of plant frost injury by nonlinear fitting of an S-shaped function. Cryo-Letters 12:47-52.

Johnson, D.E. and G.S. Howell. 1981a. Factors influencing critical temperatures for spring freeze damage to developing primary shoots on Concord grapevines. Amer. J. Enol. Viticult. 32:144-149.

Johnson, D.E. and G.S. Howell. 1981b. The effect of cane morphology and cultivar on the phenological development and critical temperatures of primary buds on grape canes. J. Amer. Soc. Hort. Sci. 106:545-549.

Lim, C.C., R. Arora, and E.C. Townsend. 1998. Comparing Gompertz and Richards functions to estimate freezing injury in Rhododendron using electrolyte leakage. J. Amer. Soc. Hort. Sci. 123:246-252.

Luoranen, J., T. Repo, and J. Lappi. 2004. Assessment of the frost hardiness of shoots of silver birch (Betula pendula) seedlings with and without controlled exposure to freezing. Can. J. For. Res. 34:1108-1118.

Palta, J.P., J. Levitt, and E.J. Stadelmann. 1977a. Freezing injury in onion bulb cells: I. Evaluation of the conductivity method and analysis of ion and sugar efflux from injured cells. Plant Physiol. 60:393-397.

Palta, J.P., J. Levitt, and E.J. Stadelmann. 1977b. Freezing injury in onion bulb cells: II. Post-thawing injury and recovery. Plant Physiol. 60:398-401.

Palta, J.P., L.S. Weiss, J.F. Harbage, J.B. Bamberg, and J.M. Stone. 1993. Molecular mechanism of freeze-thaw injury and cold acclimation in herbaceous plants: Merging physiological and genetic approaches, $\mathrm{p}$. 659-680. In: M.B. Jackson and C.R. Black (eds.). Interacting stresses in plants in a changing climate. Springer-Verlag, Berlin.

Proebsting, E.L. 1963. The role of air temperatures and bud development in determining hardiness of dormant Elberta peach fruit buds. Proc. Amer. Soc. Hort. Sci. 83:259-269.

Proebsting, E.L. 1970. Relation of fall and winter temperatures to flower bud behavior and wood hardiness of deciduous fruit trees. HortScience 5:422-424.

Proebsting, E.L. and H.H. Mills. 1978. Low temperature resistance of developing flower buds of six deciduous fruit species. J. Amer. Soc. Hort. Sci. 103:192-198.

Quamme,H.A. 1995. Deep supercooling in buds of woody plants, p.183199. In: R.E. Lee, Jr., G.J. Warren, and L.V. Gusta (eds.). Biological ice nucleation and its applications. APS Press, St. Paul, Minn.
Quamme, H.A., W.A. Su, and L.J. Veto. 1995. Anatomical features facilitating supercooling of the flower within the dormant peach flower bud. J. Amer. Soc. Hort. Sci. 120:814-822.

Ratkowsky, D.A. 1990. Handbook of nonlinear regression models. Marcel Dekker, New York.

Reader, R.J. 1979. Flower cold hardiness: A potential determinant of the flowering sequence exhibited by bog ericads. Can. J. Bot. 57:997-999.

Roberts, S.L. and I.E. DeMoranville. 1985. Spring frost tolerance, fall frost tolerance. Univ. Mass. Ext. Serv., East Wareham, Mass.

Robson, D.J., W.J. McHardy, and J.A. Petty. 1988. Freezing in conifer xylem. II. Pit aspiration and bubble formation. J. Expt. Bot. 39:1617-1621.

Robson, D.J. and J.A. Petty. 1987. Freezing in conifer xylem. I. Pressure changes and growth velocity of ice. J. Expt. Bot. 38:1901-1908.

Rodrigo, J. 2000. Spring frosts in deciduous fruit trees - Morphological damage and flower hardiness. Scientia Hort. 85:155-173.

Rutten, D. and K.A. Santarius. 1992. Age-related differences in frost sensitivity of the photosynthetic apparatus of two Plagiomnium species. Planta 187:224-229.

Sakai, A. and W. Larcher. 1987. Frost survival of plants: Responses and adaptation to freezing stress. Springer-Verlag, Berlin.

Sperry, J.S. and D.J. Dobson. 2001. Xylem cavitation and freezing in conifers, p. 121-136. In: F.J. Bigras and S.J. Colombo (eds.). Conifer cold hardiness. Kluwer, Norwell, Mass.

Spiers, J.M. 1978. Effect of bud development on cold injury in rabbiteye blueberry. J. Amer. Soc. Hort. Sci. 103:452-455.

Steffen, K.L., R. Arora, and J.P. Palta. 1989. Relative sensitivity of photosynthesis and respiration to freeze-thaw stress in herbaceous species: Importance of realistic freeze-thaw protocols. Plant Physiol. 89:1372-1379.

Stergios, B.G. and G.S. Howell, Jr. 1973. Evaluation of viability tests for cold stressed plants. J. Amer. Soc. Hort. Sci. 98:325-330.

Sutinen, M-L., J.P. Palta, and P.B. Reich. 1992. Seasonal differences in freezing stress resistance of needles of Pinus nigra and Pinus resinosa: Evaluation of the electrolyte leakage method. Tree Physiol. 11:241-254.

Tewari, A.K. and B.C. Tripathy. 1998. Temperature-stress-induced impairment of chlorophyll biosynthetic reactions in cucumber and wheat. Plant Physiol. 117:851-858.

von Fircks, H.A. and T. Verwijst. 1993. Plant viability as a function of temperature stress. Plant Physiol. 103:125-130.

Workmaster, B.A., J.P. Palta, and T.R. Roper. 1997. Terminology for cranberry bud development and growth. Cranberries 61:11-14.

Workmaster, B.A.A., J.P. Palta, and M. Wisniewski. 1999. Ice nucleation and propagation in cranberry uprights and fruit using infrared video thermography. J. Amer. Soc. Hort. Sci. 124:619-625.

Zatlyny, A.M., J.T.A. Proctor, and J.A. Sullivan. 1996. Assessing cold hardiness of red raspberry genotypes in the laboratory and field. J. Amer. Soc. Hort. Sci. 121:495-500.

Zhu, G.H. and Z.Q. Liu. 1987. Determination of median lethal temperature using logistic function, p. 291-298. In: P.H. Li (ed.). Plant cold hardiness. Alan R. Liss, New York. 